\title{
Community resources for mental health care in India
}

\author{
R. SRINIVASA MURTHY
}

India faced many challenges at the time of independence in 1947. India has a long history of medicine and political organisation. However, the situation with regard to health and mental health in 1947 was not satisfactory.

In 1947, for a population of over 300 million, there were only a handful of psychiatrists, only 10,000 psychiatric beds (one bed per 30,000 population), there were no training centres of psychiatry, the legislation governing the mentally ill was the Indian Lunacy Act 1912, the expectation of life at birth was 35 years. However, there was high tolerance by the community and emotional commitment of families to the mentally ill individuals.

In 1999 , the population has tripled to 1000 million, the number of psychiatrists are about 3000 , there are over 30,000 psychiatric beds, about 50 centres provide postgraduate training in psychiatry, the legislation has been updated (Mental Health Act 1987), a new positive law Persons With Disabilities Act, 1995 is in place, the life expectancy at birth is 65 years and about $30 \%$ of the population live in urban areas. The positive features or community tolerance/acceptance and the family support for the mentally ill continues.

The situation in 1947 presented many challenges to Indian psychiatrists. A striking feature of the last 50 years is the continuous and systematic efforts by psychiatrists to innovate to meet the mental health needs of the population and to utilise the community resources for mental health care. These efforts of Indian professionals have relevance to other developing countries and to the development of community mental health movement in the world.

Indirizzo per la corrispondenza: Professor R.S. Murthy, National Institute of Mental Health \& Neuro Sciences, Bangalore 560029 (India).

Fax: $+91-80-663.1830$

E-mail: murthy@nimhans.kar.nic.in
The approaches have involved planning from the community level and utilizing all the resources in the community for mental health care. This has involved:

- integration of mental health care with primary care services

- working with patients and families,

- , development of community based facilities like daycare centres, rehabilitation facilities, crisis centres, and halfway homes.

- promotion of mental health using schools and traditional practices in the community

- legal and judicial initiatives towards rights of the mentally ill persons, and

- formulation of national program of mental health. The most striking aspect of recent mental health care in India is the choice of community mental health care as the primary approach to providing care to the general population. A series of studies of prevalence of mental disorders in primary health care were carried out. These studies showed that these disorders are frequent and further the general physicians are not recognising them and treating them appropriately (Harding et al., 1980; Shamsundar et al., 1978; 1986; Gautam et al., 1980; Channabasavanna et al., 1995).

The initial efforts were to develop simple and short duration training programs of mental health for the primary health care personnel (Isaac et al., 1982; Shamsundar et al., 1978; 1980; 1983; Wig \& Murthy, 1981). Models for population units of $1,00,000$ were taken up and evaluated (Wig et al., 1981). The next major step was to develop a model covering a population unit of 2 million.

The basic approaches included:

1. a decentralized training program at the local level

2. provision of mental health care in all general health facilities

3. involvement of all categories of health and welfare personnel

4. provision of five essential psychotropic drugs

5. a simple record keeping system 
6. a mechanism of monitoring the work of the primary health care personnel in the provision of mental health care and

7. a mental health team for referral support.

The results of the project (1985-1990) showed that it is possible to provide basic mental health care with primary health care services. The experience has greater relevance, as the direct involvement of mental health professionals was limited. (Murthy, 1996)

Manuals of mental health for different categories of health personnel, recording system, training videos, assessment forms, and public education materials have been developed (Isaac et al., 1994; Sriram et al., 1987). The growth of primary health care level mental health initiatives is in line with the other initiatives in general health care for other health problems like tuberculosis, leprosy and family welfare.

These efforts resulted in the formulation of the $\mathrm{Na}$ tional Mental Health Program of India (1982). The formulation of the NMHP in 1982 was a milestone in the history of mental health care. The main objective of NMHP is «to ensure availability and accessibility of minimum mental health care for all in the foreseeable future, particularly to the most vulnerable and underprivileged sections of the population».

Following the formulation of the NMHP, Indian health plans have included mental health as one of the National Programs. Both central and state level initiatives are resulting in mechanisms for mental health planning. The NMHP has proved to be the rallying point for professionals, planners, politicians, and the general public. The five-year plans since 1982 have provided support for mental health programs.

A similar approach of integrating mental health care with general health care has been utilised to meet the needs of special populations like disaster affected populations (Murthy et al., 1987). A recent development is the focus on economics of common mental disorders in primary health care (Chisholm et al., 1999) and evaluation of interventions using a research design (Patel, in press).

Majority of the mentally ill live in the community together with their family. Indian psychiatry has considered families of the mentally ill an integral part of care programs. As early as in the 1950 's, patients were admitted for treatment with family members (Kohmeyer \& Fernandes, 1963; Chacko, 1967). Studies were carried out to compare the impact of family treatment (Narayanan \& Reddy, 1977; Narayanan, 1977; Geetha, 1980; Pai \& Kapur, 1981; 1982; 1983; Pai \& Nagarajaiah, 1983;
Pai et al., 1983). In the last two decades, the efforts have been to provide support to families (Suman et al., 1980), understand the role of family interactions and expressed emotions in the course and outcome of schizophrenia (Bhatti, 1980; Bhatti et al., 1980; Wig et al., 1987). During the last one decade the movement has included development of (1) family education programs, (2) family interventions, (3) formation of self-help groups, (4) fighting stigma and discrimination experienced by patients and their families (Shankar \& Menon, 1991; Shankar, 1994; Murthy, 1999). The newer legislative provisions are also more family friendly and supportive.

A very striking aspect of family work in India is the cooperation and collaboration between families and mental health professionals and avoidance of the confrontationist approaches often reported from other countries.

The school mental health programs have focussed on the care of the ill children, prevention and promotion of mental disorders. The initial efforts were to consider the school teachers as first level care providers. Focussed programs were developed at a number of centres in India, specially at Bangalore (Kapur \& Cariappa, 1979). The recent efforts have been focussed on use of life skills programs in promotion of mental disorders (Kapur, 1997; Murthy, 1992).

The problems of drug dependence, especially of substances that have had a wide cultural acceptance throughout history (e.g. cannabis, opium) call for nonclinical and noninstitutional approaches. A major innovations is to change the paradigm of care from hospital to community, and to direct the deaddiction process into a community activity. This has been successfully shown to be possible for both the problems of opium use and alcohol use. (Ranganathan, 1996).

Mental health professionals are very few and largely located in urban areas. All over the world, volunteers play an important role in addressing problems like attempted suicide. In India, lay volunteers are providing crisis intervention services in the major metropolitan cities of Bangalore, Bombay, Delhi, Calcutta, Hyderabad, Madras, Pondicherry, and Calicut. There are also programs to train volunteers to work in small community level institutions like hostels and half way houses (Murthy, 1992).

Another major initiative is the community education and community involvement. The mass media, especially radio and television, have developed public education programs on drugs, alcohol, tobacco (DATE), and mental disorders (MINDWATCH). The media have also focussed on the issues of mental hospitals, women in institutions, and mental retardation. This is an ongoing activity. 
Along with the above activities, there have been supportive legislative changes.

In 1987, the new Mental Health act was enacted. This is a progressive Act with provision for voluntary admission, short duration admission under special situations, and administrative structures for developing and monitoring mental health programs at the central and state levels. The human rights of the mentally ill are given priority.

The most recent initiative is the enactment of The Persons With Disabilities Act (PDA) 1995, guaranteeing equal opportunities, protection of rights, and full participation. This is a major milestone in the welfare policies of India. The PDA 1995 includes mental retardation and mental illness under the definition of disability. The Act provides for education, employment, social security, nondiscrimination, affirmative action, prevention, research, and manpower development. There are also statutory bodies for implementing the Act at the central and state levels (Murthy, 1999).

India has made rapid progress in the last 50 years and poised to take its place in the community of nations $(\mathrm{Ka}$ laam \& Rajan, 1998; Karlekar, 1998). Psychiatry in India is showing strong signs of growth and the development of culturally sensitive responses. These efforts are, at this time, not well organised and research studies are not longitudinal. However, the examination of mental disorders, their antecedents, and care patterns are resulting in a reexamination of long held concepts and patterns of care. With larger numbers of professionals joining these efforts, there will be greater relevance of Indian experiences of community care. This is an opportunity for psychiatry to grow worldwide.

\section{REFERENCES}

Bhatti R.S. (1980). Psychiatric family ward treatment: 1. An appraisal. 2. How to select a relative to stay with the patient. Family Process $19,193-200$.

Bhatti R.S., Janakiramaiah N., Channabasavanna S.M. \& Shoba Devi (1980). Descriptive and manifestation of multiple family group interaction. Indian Journal of Psychiatry 22, 51-55.

Chacko R. (1967). Family participation in the treatment and rehabilitation of the mentally ill. Indian Journal of Psychiatry 9, 328-33.

Channabasavanna S.M.,Sriram T.G. \& Kumar K. (1995). Results from the Bangalore centre. In Mental lllness in General Health Care. An International Study (ed. T.B. Ustün and N. Sartorius N.). Wiley: Chichester.

Chisholm D., Sekar K., Kishore Kumar, Saeed K., James S., Mubbasher M. \& Murthy R.S. (1999). Integration of mental health care into primary care: a demonstration cost-outcome study in India and Pakistan. British Journal of Psychiatry (in press).

Gautam S., Kapur R.L. \& Shamasundar C. (1980). Psychiatric morbi- dity and referral in general practice. Indian Journal of Psychiatry 22, 295-297.

Geetha P.R. (1980). The study of efficacy of family ward treatment in hysteria in comparison with the open ward and the outpatient treatment. Indian Journal of Psychiatry 22, 317-323.

Harding T.W., De Arango M.V., Batazar J., Climent C.E., Ibrahim H.H., Ladrido-Ignacio L., Murthy R.S. \& Wig N.N. (1980). Mental disorders in primary health care: a study of their frequency and diagnosis in developing countries. Psychological Medicine 10, 231241.

Isaac M.K., Kapur R.L., Chandrasekhar C.R., Kapur M. \& Parthasarathy R. (1982) Mental health delivery in rural primary health care - development and evaluation of a pilot training programme. $I n$ dian Journal of Psychiatry 24, 131-132.

Isaac M.K., Chandrasekhar C.R. \& Murthy R.S. (1994). Mental Health Care by Primary Care Doctors. NIMHANS: Bangalore.

Kalaam A.P.J.A. \& Rajan Y.S. (1998). India 2020: a Vision for the New Millennium. Viking: New Delhi.

Kapur M. (1997). Mental Health in Indian Schools. Sage: New Delhi.

Kapur M \& Cariappa I. (1979). Training counselling of school teachers. International Joumal of Advance Counselling 2, 109-114.

Karlekar H. (1998). Independent India: the First Fifty Years. Oxford: Delhi.

Kohmeyer W.A. \& Fernandes X. (1963). Psychiatry in India: family approach in the treatment of mental disorders. American Journal of Psychiatry 119, 1033-38.

Murthy R.S. (1992). Mental health. In State of India's Health (ed. A. Mukhopadhyaya), pp. 400-414. Voluntary Health Association of India: New Delhi.

Murthy R.S. (1996). Economics of mental health care in developing countries. In International Review of Psychiatry, vol. 2. (ed. F Lieh Mak and C Nadelson), pp. 43-62. American Psychiatric Press: Washington DC.

Murthy R.S. (1998). Psychiatry in the third world: managing and rationalising health care. Current Opinion in Psychiatry 11, 197-199.

Murthy R.S. (1999a). Indian formulates a new act for the disabled persons. NIVM Newsletter 5, 5-6.

Murthy R.S. (1999b). Approaches to organising mental health services in developing countries with limited resources . In One World, One Language: Paving the Way to Better Perspectives or Mental Health (ed. J. Lopez-Ibor, F. Lieh-Mak, H.M. Visostsy and M. Maj). Hogrefe and Haber: Hamburg.

Murthy R.S. (1999c). Socialisation and mental health in India. In $\mathrm{Cul}$ ture, Socialisation and Human Development (ed. T.S. Saraswathi), pp. 378-397. Sage: New Delhi.

Murthy R.S., Isaac M.K., Chandrasekhar C.R. \& Bhide A.S. (1987). Manual of Mental Health for Medical Officers - Bhopal Disaster. ICMR: New Delhi.

Narayanan H.S. \& Reddy G.N.N. (1977). Review of treatment in family ward. Indian Journal of Psychiatry 14, 123-126.

Narayanan H.S. (1977). Experience of group and family therapy in India. International Journal of Group Psychotherapy 27, 517-519.

National Mental Health Programme for India.(1982). Directorate General of Health Service, New Delhi.

Pai S. \& Kapur R.L. (1981). The burden on the family of a psychiatric patient: development of an interview schedule. British Journal of Psychiatry 138, 332-335.

Pai S. \& Kapur R.L. (1982). Impact on treatment intervention on the relationship between the dimensions of clinical psychopathology, social dysfunction and burden on families of schizophrenic patients. Psychological Medicine 12, 651-658. 


\section{R. Srinivasa Murthy}

Pai S. \& Kapur R.L. (1983). Evaluation of home care treatment for schizophrenic patients. Acta Psychiatrica Scandinavica 67, 80-88.

Pai S. \& Nagarajaiah. (1982). Treatment of schizophrenic patients in their homes through a visiting nurse: some issues in nurses training. Journal of Nursing Studies 19, 167-172.

Pai S., Kapur R.L. \& Roberts E.J. (1983). Follow up study of schizophrenic patients initially treated with home care. British Journal of Psychiatry 143, 447-450.

Patel V. (in press). The need for treatment evidence for common mental disorders in developing countries. Psychological Medicine.

Ranganathan S. (1996). The Empowered Community: a Paradigm Shift in the Treatment of Alcoholism. TTR Clinical Research Foundation: Madras.

Shamasundar C., Kapur R.L.,Sundaram U.K., Pai S. \& Nagarathna G.N. (1978). Involvement of the GPs in urban mental health care. Journal of Indian Medical Association 72, 310-313.

Shamasundar C., Sundaram U.K., Kalyanasundaram S., Pai S. \& Kapur R.L. (1980). Training of GPs in mental health - two-year experience. Indian Journal of Psychological Medicine 3, 85-89.

Shamasundar C., Kapur R.L., Isaac M.K. \& Sundaram U.K. (1983). Orientation course in psychiatry for GPs. Indian Journal of Psychiatry 25, 298.

Shamasundar C., Krishnamurthy S., Om Prakash, Prabhakar N. \& Subbakrishna D.K.(1986). Psychiatric morbidity in general practice in an Indian city. British Medical Journal 292, 1713-1714.

Shankar R. (1994). Interventions with families of people with schi- zophrenia in India. In Family Interventions in Mental Illness (ed. A.B. Hatfield), pp. 79-88. New Directions for mental health services 62 .

Shankar R. \& Menon M.S. (1991). Interventions with families of people with schizophrenia: the issues facing community based rehabilitation in India. Psychosocial Rehabilitation Journal 15, 85-90.

Sriram T.G., Kishore Kumar, Moily S., Chandrashekar C.R., Isaac M.K. \& Murthy R.S. (1987). Minor psychiatric disturbances in primary health care: a study of their prevalence and characteristics using a simple case detection technique. Indian Journal of Social Psychiatry 3, 212-226.

Suman C., Baldev S., Murthy R.S. \& Wig N.N. (1980). Helping chronic schizohrenics and their families in the community: initial observations. Indian Journal of Psychiatry 22, 97-102.

Wig N.N. \& Murthy R.S. (1981). Manual of Mental Health for Primary Care Personnel. Indian Council of Medical Research: New Delhi.

Wig N.N., Murthy R.S. \& Harding T.W. (1981). A model for rural psychiatric services - Raipur Rani experience. Indian Journal of Psychiatry 23, 275-290.

Wig N.N., Menon D.K., Bedi H., Leff J., Kuipers L., Ghosh A., Day R., Morten A., Erdberg U., Sartorius N. \& Jablensky A. (1987). Distribution of expressed emotions components among relatives of schizophrenic patients in Aarrhus and Chandigarh. British Journal of Psychiatry 151, 160-165. 